\title{
Influencing and Interpreting Visual Input: The Role of a Visual Feedback System
}

\author{
Edward Gruberg, ${ }^{1}$ Elizabeth Dudkin, ${ }^{2}$ Yuan Wang, ${ }^{3}$ Gonzalo Marín, ${ }^{4}$ Carlos Salas, ${ }^{4}$ Elisa Sentis, ${ }^{4}$ Juan Letelier, ${ }^{4}$ \\ Jorge Mpodozis, ${ }^{4}$ Joseph Malpeli, ${ }^{5} \mathrm{He}$ Cui, ${ }^{5}$ Rui Ma, ${ }^{5}$ David Northmore, ${ }^{6}$ and Susan Udin ${ }^{7}$ \\ ${ }^{1}$ Department of Biology, Temple University, Philadelphia, Pennsylvania 19122, ${ }^{2}$ Department of Biology, Pennsylvania State University, Media, Pennsylvania \\ 19063, ${ }^{3}$ Department of Otolaryngology, University of Washington, Seattle, Washington 98195, ${ }^{4}$ Department of Biology, University of Chile, Santiago de \\ Chile, ${ }^{5}$ Department of Psychology, University of Illinois at Urbana-Champaign, Champaign, Illinois 61820, ${ }^{6}$ Department of Psychology, University of \\ Delaware, Newark, Delaware 19716, and 7Department of Physiology and Biophysics, State University of New York at Buffalo, Buffalo, New York 14260
}

Vertebrates are able to visually identify moving objects and orient toward attractive ones or escape if the objects seem threatening. When there is more than one object in the visual field, they can attend to a particular object. The optic tectum (superior colliculus in mammals) (OT/SC) has long been known to mediate such functions (Schneider, 1969; Ingle, 1973a). Less well known is that the OT/SC is strongly affected by a smaller midbrain area called nucleus isthmi (parabigeminal nucleus in mammals) (NI/PB). We discuss how NI/PB influences OT/SC function and visual behavior.

Anatomically, OT/SC makes reciprocal, topographic connections with ipsilateral NI/PB. Adjacent points in OT/SC project to adjacent points in NI/PB. The return projections from NI/PB terminate in many of the same superficial layers as retinotectal fibers, and their effects on tectal processing may facilitate selection of a single stimulus from an array of potential targets. In amphibians and mammals, NI/PB also project to the contralateral OT/SC (Fig. 1).

\section{Visual behavior and the frog NI}

When presented with a single prey stimulus anywhere in its visual field, a frog will approach and attack the stimulus. When presented with two prey stimuli, they will select one of the stimuli (Ingle, 1973b; Stull and Gruberg, 1998). After ablation of the optic tectum, frogs will not respond to prey stimuli (or to looming stimuli), although they retain other visual abilities, such as perceiving stationary objects (Ingle, 1973b).

Other than the retina, the greatest input to the OT in frogs comes from NI. It can be divided into two functionally discrete regions: one region makes topographic reciprocal connections with the ipsilateral OT; the other region projects topographically to the contralateral tectal lobe. Unilateral ablation of NI results in a scotoma in the contralateral monocular visual field (Gruberg et al., 1991) that is similar to unilateral ablation of the OT. Partial ablation of NI results in a smaller scotoma that always includes the posteriormost part of the monocular field. Within the sco-

Received July 31, 2006; revised Sept. 4, 2006; accepted Sept. 11, 2006.

Correspondence should be addressed to Edward Gruberg, Department of Biology, Temple University, 1900 North 12th Street, Philadelphia, PA 19122. E-mail: e.gruberg@temple.edu.

D0I:10.1523/JNEUROSCI.3288-06.2006

Copyright $\odot 2006$ Society for Neuroscience $\quad$ 0270-6474/06/2610368-04\$15.00/0 toma, the behavioral threshold to prey stimuli is considerably increased and resembles visual neglect.

NI directly influences retinotectal transmission (King and Schmidt, 1991; Dudkin and Gruberg, 2003). Frog isthmotectal fibers are cholinergic (Desan et al., 1987; Wallace et al., 1990) and terminate in retino-recipient layers of the optic tectum. Retinal ganglion cell axons express nicotinic acetylcholine (ACh) receptors (Sargent et al., 1989). There do not appear to be conventional synapses between isthmotectal fibers and retinotectal axons (Gruberg et al., 1994). Nonetheless, by selectively filling retinotectal fibers with a fluorescent calcium-sensitive dye, NI influence on retinotectal fibers can be shown. Single-shock stimulation to the optic nerve causes a brief increase in fluorescence. Singleshock stimulation to NI causes no change in fluorescence. When single-shock stimulation of NI is paired with optic nerve stimulation, there is a greater than twofold increase in fluorescence compared with single-shock stimulation of the optic nerve alone (Dudkin and Gruberg, 2003). The behavioral and physiological results suggest that, in most of the visual field, retinotectal signals require input from NI to reach behavioral threshold.

\section{Morphological substrates of feature detection in the bird isthmotectal system}

What is the OT/NI circuitry that could account for visual recognition and attention? As with amphibians, birds select particular objects for their attention. Birds have a more elaborate set of connections between the OT and NI than amphibians. In the bird NI, morphologically and biochemically distinct neurons are arranged in three separate clusters, each having a unique connection with the OT (Fig. 2). The nucleus isthmi pars parvocellularis (Ipc) and pars semilunaris (SLu) contain cholinergic neurons and maintain precise homotopic reciprocal connections with OT. Their columnar axonal terminals pass through a great depth of the OT and selectively arborize in certain tectal layers (Wang et al., 2006). In contrast, neurons in the nucleus isthmi pars magnocellularis (Imc) are rich in GABA and receive a coarse topographical projection from the OT (Wang et al., 2004). One type of Imc neuron, Imc-Te, projects back widely to the OT in a heterotopic manner, whereas the other, Imc-Is, innervates both Ipc and SLu. These isthmotectal and isthmo-isthmic interactions, as well as intrinsic connections across OT layers, constitute a well organized neuronal network and enable the participation of NI in OT feature detection. Imc and Ipc may influence the responsiveness 


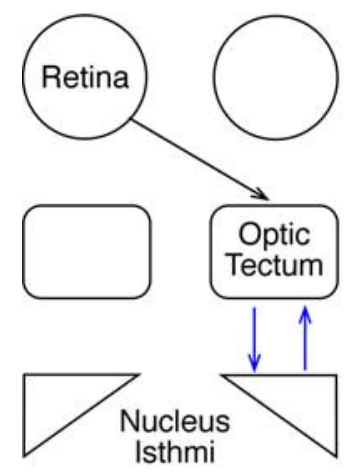

Bony Fish

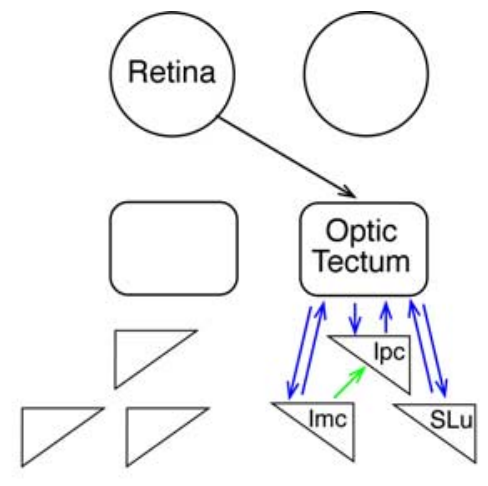

Birds

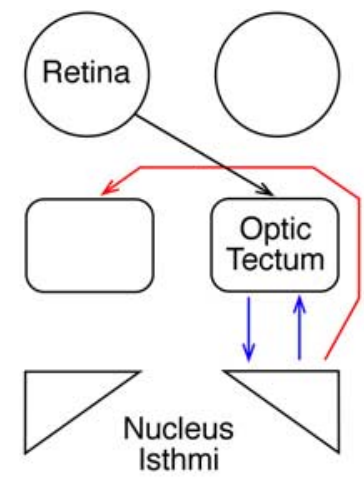

Amphibians

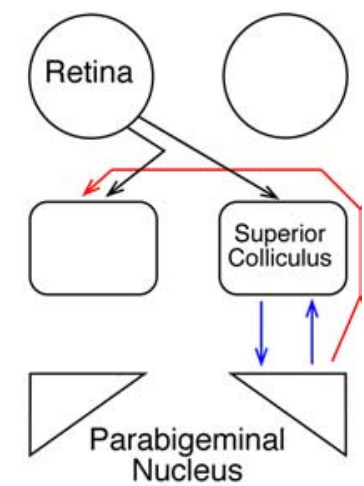

Mammals

Figure 1. Basic connections between the retina, $0 \mathrm{~T} / \mathrm{SC}$, and NI/PB in various classes of vertebrates. In all animals studied, there are reciprocal topographic connections between the $0 \mathrm{~T} / \mathrm{SC}$ and $\mathrm{NI} / \mathrm{PB}$ (blue). Birds and reptiles have more than one isthmic nucleus. Amphibians and mammals have significant crossed connections (red) from NI/PB to OT/SC.

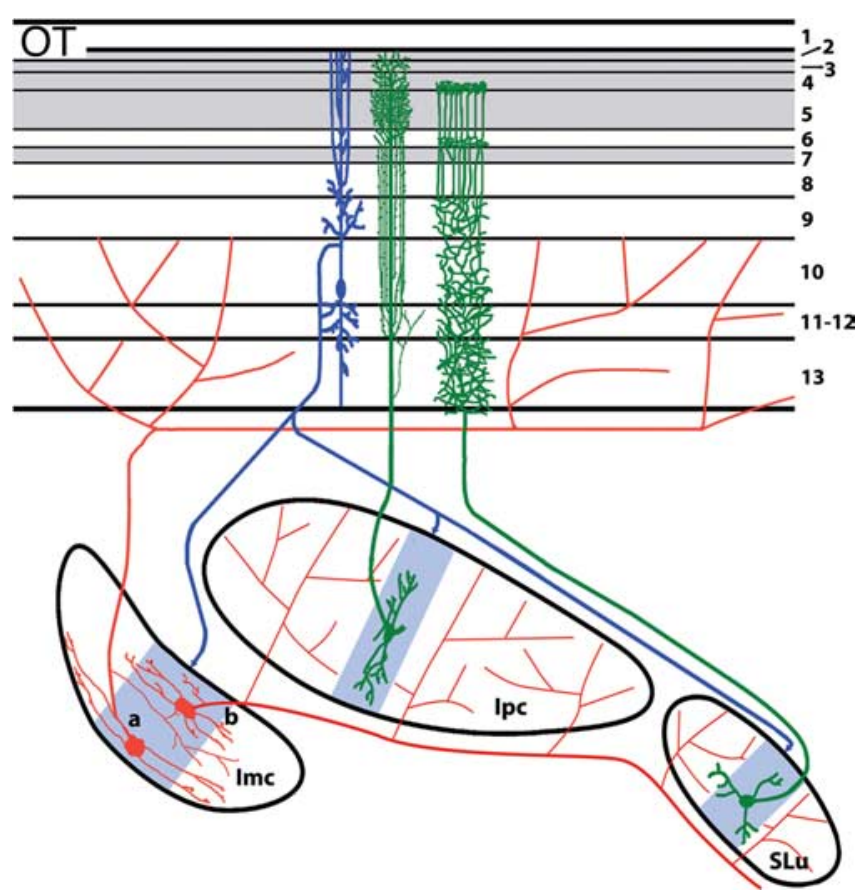

Figure 2. Connections between the OT and three divisions of the bird nucleus isthmi: Ipc, SLu, and Imc. Radial tectal neurons (blue) in the tectal layer 10b project topographically on Imc, Ipc, and SLu. Imc-Is neurons (a) and Imc-Te neurons (b) project widely on Ipc/SLu and OT, respectively. Ipc and SLu axons (green) terminate in narrow columnar arrays within certain tectal layers. The gray shading of the OT indicates retino-recipient tectal layers. The blue shading within Imc, Ipc, and SLu, indicates tectal termination.

of OT neurons and thus draw visual attention to the most salient visual targets and their features (Wang et al., 2000). Alternately, Ipc and SLu may act on specific feature-detecting circuitries, such as motion-detecting tectal ganglion cells, and provide synchronous activation within individual motion-detecting channels or across several such channels.

\section{The bird isthmotectal network as a spatial attentional mechanism}

The anatomical relationship between NI and OT described above for birds suggests that the NI-mediated cholinergic feedback impinging on one tectal locus could compete with feedback produced at other tectal loci via long distance suppressive interactions mediated by Imc. These interactions may have an atten- tional effect, by focusing the cholinergic feedback at one or few tectal locations at any given time. The cholinergic input from NI is visually evoked and leads to oscillatory bursting potentials recorded across tectal layers. They are generated by the bursting firing of "paintbrush" axon terminals from the Ipc (Marin et al., 2005). Wide-field competition could be mediated by the diffuse GABAergic projection from the Imc to Ipc and the OT (Fig. 3). Indeed, during simultaneous extracellular recordings in the nucleus isthmi of anesthetized pigeons, bursting visual responses in an Ipc locus can be totally suppressed by a second stimulus presented up to $>100^{\circ}$ of visual angle separation. This long-distance suppression is mediated by Imc (G. Marín, C. Salas, E. Sentis, J. Letelier, and J. Mpodozis, unpublished results).

The NI-mediated focal signals may be specifically directed to the dendritic "bottlebrushes" of tectal ganglion cells (Wang et al., 2006), whose axons contribute to the ascending pathway to the diencephalic nucleus rotundus (RT) (caudal pulvinar of mammals) (Karten et al., 1997; Major et al., 2000). In birds, paintbrush terminals from Ipc are particularly dense in tectal layer five, intermingling with both retinotectal terminals and dendritic bottlebrushes of a specific population of tectal ganglion cells that project to the dorsal anterior subdivision of the RT. The visually evoked, extracellular responses in these subdivisions of the RT are closely synchronized to tectal OBs (G. Marín, C. Salas, J. Letelier, and J. Mpodozis, unpublished results) (Fig. 3), suggesting that the bursting firing of the cholinergic paintbrushes may exert a fast gating control on the flow of visual activity ascending to the telencephalon. These observations are in line with the hypothesis derived from study of the frog that retinotectal transmission requires input from NI to reach perceptual threshold.

\section{Cat PB computation of error signals during tracking of moving targets}

How is NI/PB used in other classes of vertebrates? In many mammalian species, the eyes move to track visual stimuli. This function is mediated in part by the SC. In the anesthetized cat, PB cells respond to visual stimuli in a way similar to SC cells and are organized visuotopically (Graybiel, 1978; Sherk, 1979a,b). In the awake cat, $\mathrm{PB}$ cells encode retinal position error (RPE), the angle between gaze direction and a visually pursued target (Cui and Malpeli, 2003). When a moving target suddenly appears, a short transient burst is followed by a firing rate that is continuously related to the magnitude and direction of RPE as the cat tracks the target with a series of catch-up saccades. Typically, activity 
increases virtually linearly with RPE in some preferred direction, peaks at an optimal RPE, and then declines slowly with additional RPE increases.

The PB also appears to encode RPE even for virtual targets: targets not visible, but whose position can be inferred. When a cat tracks a moving laser spot that is blinking on and off, the relationship between activity and RPE is similar for both On (real target) and Off (virtual target) phases of the spot. Activity peaks at some best RPE, whether the target is real or virtual, although it is significantly lower in magnitude for the latter. There is similar activity in the SC, but for a smaller fraction of cells, and with smaller responses to the virtual target. Still to be distinguished is cause and effect: does the response initially arise in the $\mathrm{SC}$ or the $\mathrm{PB}$ ?

\section{In teleost fishes, NI does not care what it is or where it is, just so long as it stays away}

In teleost fishes, NI appears to be configured to recognize looming objects. As described above, the OT and NI are reciprocally connected in topographic manner (Sakamoto et al., 1981; Dunn-Meynell and Sharma, 1984; Xue et al., 2001). NI generates bursts of graded amplitude spikes evoked by visual and mechanoreceptor stimulation. Change, especially motion, throughout the field of the contralateral eye is an effective visual stimulus (Northmore, 1991). Despite the topographic mapping, electrophysiological probing across NI surprisingly shows no visuotopic organization. Recordings of single NI neurons reveal whole-field responsiveness (Northmore et al., 1990). Moreover, electrodes at opposite ends of NI yield virtually identical spike waveforms, suggesting that NI functions as a unit (Northmore and Gallagher, 2003), possibly mediated by electrical coupling (Williams and Vanegas, 1982). Isthmotectal feedback is evident in deep tectum. Here spiking activity closely mirrors NI spiking (Northmore and Gallagher, 2003); NI and OT spikes synchronize within a fraction of a millisecond. Consequently, activity all over deep OT appears to be doing the same thing and, in time with NI, violating any expectations of reciprocal topography.

So what does fish NI do? Its hair-trigger response to novelty and motion broadcast over the OT suggests an alerting or attentional function, an idea supported by the finding that NI can be "distracted" by a salient ipsilateral stimulus (Northmore, 1991). The crossing pathway mediating this effect could involve the inhibitory prectecto-isthmal fibers (Sakamoto et al., 1981; DunnMeynell and Sharma, 1984; Xue et al., 2001). The most effective visual stimulus for $\mathrm{NI}$ is an object advancing toward the contralateral eye (Gallagher and Northmore, 2006), evoking a linear ramp-up in firing. The instantaneous activity level seems to represent object nearness, which it does somewhat independently of speed and size, using only monocular motion cues. NI then informs its corresponding tectal lobe of "general nearness" in contralateral space and biases the premotor output of the tectum accordingly, presumably to avoid things that are coming too close for comfort (Northmore and Graham, 2005).

\section{Aligning retinotectal and isthmotectal maps in the frog}

Finally, how do retinotectal fibers align with isthmotectal tectal fibers to create a unitary visuotopic map? Feedback from the crossed isthmotectal axons to the retinotectal terminals may play a key role in the developmental matching of the tectal maps of the two eyes. The establishment of an orderly map of the input of the ipsilateral eye, relayed by the crossed isthmotectal axons, is a two-stage process (Udin and Grant, 1999). Initially, chemoaffinity cues dominate; this conclusion is based on the observation that the maps initially develop normally in frogs that have been reared in the dark or with one eye rotated. The effects of dark rearing or of rotating one eye in tadpoles imply that, at first, chemoaffinity cues dominate, because the maps initially develop normally. However, visual cues start to dominate after a few weeks of abnormal visual experience: in dark-reared animals, ipsilateral map topography deteriorates, and, in animals with eye rotations, the axons develop new connections that bring the ipsilateral map into conformity with the contralateral map.

The simplest model for the activity-dependent aspect of ipsilateral map formation is that, whenever isthmotectal and retinotectal axons with matching receptive fields converge on a tectal dendrite, their temporally correlated firing activates NMDA receptors and triggers events that stabilize the isthmotectal branches. Recent data, however, support only parts of this model. NMDA receptors are crucially involved in activity-dependent isthmotectal plasticity. However, the isthmotectal axons (the ones that undergo the activity-dependent reorganization) are cholinergic, not glutamatergic. Moreover, they do not even synapse onto the same dendrites that get retinotectal input (Rybicka and Udin, 2005). Therefore, the simple convergence model does not apply. However, there is a way for the two populations to interact: isthmotectal axons release $\mathrm{ACh}$, and retinotectal axons have nicotinic receptors (Fig. 4). Thus, ACh released from correctly located isthmotectal branches increases glutamate output 


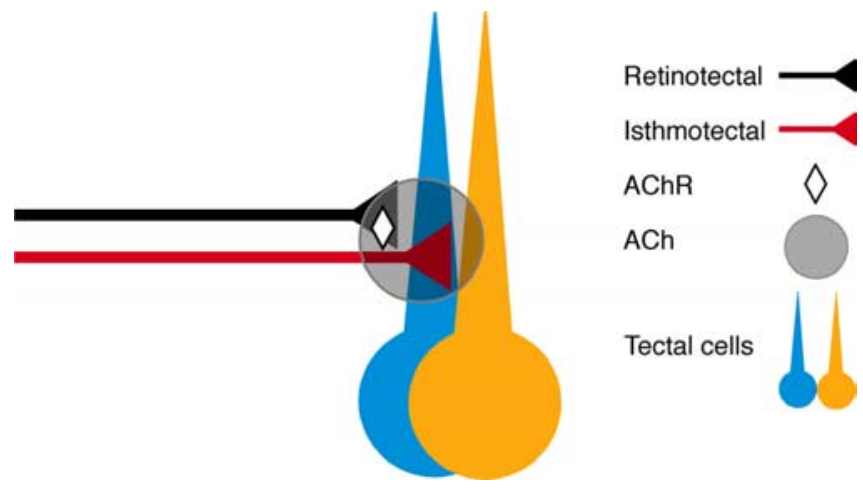

Figure 4. Stabilization of correctly situated isthmotectal connections is hypothesized to occur because ACh, which the isthmotectal axon releases, causes a boost in glutamate release by the coactive retinotectal axons. The extra glutamate promotes opening of more NMDA receptors on the retino-recipient dendrite, which in turn releases enough neurotrophin to stabilize the nearby isthmotectal axon.

from retinotectal axons when both are activated by a visual stimulus; according to this model, the additional glutamate triggers NMDA receptor opening, and subsequent release of a retrograde agent, such as BDNF, stabilizes the isthmotectal branch.

\section{Conclusion}

In summary, vertebrates have a common anatomical pattern of reciprocal connections between OT/SC and ipsilateral NI/PB. Depending on the species, the system is elastic enough to be adapted for recognizing and orienting toward attractive objects or recognizing and avoiding threatening stimuli or both. The matching of retinotectal and isthmotectal fiber systems to form an aligned visuotopic map occurs during development. This system is configured so that, when presented with several stimuli, the animal can attend to a particular one.

\section{References}

Cui H, Malpeli JG (2003) Activity in the parabigeminal nucleus during eye movements directed at moving and stationary targets. J Neurophysiol $89: 3128-3142$.

Desan PH, Gruberg ER, Grewell KM, Eckenstein F (1987) Cholinergic innervation of the optic tectum in the frog Rana pipiens. Brain Res 413:344-349.

Dudkin EA, Gruberg ER (2003) Nucleus isthmi enhances calcium influx into optic nerve fiber terminals in Rana pipiens. Brain Res 969:44-52.

Dunn-Meynell AA, Sharma SC (1984) Changes in the topographically organized connections between the nucleus isthmi and the optic tectum after partial tectal ablation in adult goldfish. J Comp Neurol 227:497-510.

Gallagher SP, Northmore DP (2006) Responses of the teleostean nucleus isthmi to looming objects and other moving stimuli. Vis Neurosci 23:209-219.

Graybiel AM (1978) A satellite system of the superior colliculus: the parabigeminal nucleus and its projections to the superficial collicular layers. Brain Res 145:365-374.

Gruberg ER, Wallace MT, Caine HS, Mote MI (1991) Behavioral and physiological consequences of unilateral ablation of the nucleus isthmi in the leopard frog. Brain Behav Evol 37:92-103.

Gruberg ER, Hughes TE, Karten HJ (1994) Synaptic interrelationships between the optic tectum and the ipsilateral nucleus isthmi in Rana pipiens. J Comp Neurol 339:353-364.

Ingle D (1973a) Two visual systems in the frog. Science 181:1053-1055.
Ingle D (1973b) Selective choice between double prey objects by frogs. Brain Behav Evol 7:127-144.

Karten HJ, Cox K, Mpodozis J (1997) Two distinct populations of tectal neurons have unique connections within the retinotectorotundal pathway of the pigeon (Columba livia). J Comp Neurol 387:449-465.

King WM, Schmidt JT (1991) The long latency component of retinotectal transmission: enhancement by stimulation of nucleus isthmi or tectobulbar tract and block by nicotinic cholinergic antagonists. Neuroscience 40:701-712.

Major DE, Luksch H, Karten HJ (2000) Bottlebrush dendritic endings and large dendritic fields: motion-detecting neurons in the mammalian tectum. J Comp Neurol 423:243-260.

Marin G, Mpodozis J, Sentis E, Ossandon T, Letelier JC (2005) Oscillatory bursts in the optic tectum of birds represent re-entrant signals from the nucleus isthmi pars parvocellularis. J Neurosci 25:7081-7089.

Northmore DP (1991) Visual responses of nucleus isthmi in a teleost fish (Lepomis macrochirus). Vision Res 31:525-535.

Northmore DP, Gallagher SP (2003) Functional relationship between nucleus isthmi and tectum in teleosts: synchrony but no topography. Vis Neurosci 20:335-348.

Northmore DP, Graham BJ (2005) Avoidance behavior controlled by a model of vertebrate midbrain mechanisms. In: International work conference on the interplay between natural and artificial computation 2005, lecture notes in computer science 3561 (Mira J, Alvarez JR, eds), pp 338 345: Springer: Berlin.

Northmore DP, Banks JR, Guthrie DM (1990) Responses of nucleus isthmi of perch recorded intracellularly and free-swimming. Invest Opthamol Vis Sci Suppl 31:394.

Rybicka KK, Udin SB (2005) Connections of isthmotectal axons and GABAimmunoreactive neurons in Xenopus tectum: an ultrastructural study. Vis Neurosci 22:305-315.

Sakamoto N, Ito H, Ueda S (1981) Topographic projections between the nucleus isthmi and the optic tectum in a teleost, Navodon modestus. Brain Res 224:225-234.

Sargent PB, Pike SH, Nadel DB, Lindstrom JM (1989) Nicotinic acetylcholine receptor-like molecules in the retina, retinotectal pathway, and optic tectum of the frog. J Neurosci 9:565-573.

Schneider GE (1969) Two visual systems. Science 163:895-902.

Sherk H (1979a) A comparison of visual-response properties in cat's parabigeminal nucleus and superior colliculus. J Neurophysiol 42:1640-1655.

Sherk H (1979b) Connections and visual-field mapping in cat's tectoparabigeminal circuit. J Neurophysiol 42:1656-1668.

Stull AK, Gruberg ER (1998) Prey selection in the leopard frog: choosing in biased and unbiased situations. Brain Behav Evol 52:37-45.

Udin SB, Grant S (1999) Plasticity in the tectum of Xenopus laevis: binocular maps. Prog Neurobiol 59:81-106.

Wallace MT, Ricciuti AJ, Gruberg ER (1990) Nucleus isthmi: its contribution to tectal acetylcholinesterase and choline acetyltransferase in the frog Rana pipiens. Neuroscience 35:627-636.

Wang Y, Xiao J, Wang SR (2000) Excitatory and inhibitory receptive fields of tectal cells are differentially modified by magnocellular and parvocellular divisions of the pigeon nucleus isthmi. J Comp Physiol A Neuroethol Sens Neural Behav Physiol 186:505-511.

Wang Y, Major DE, Karten HJ (2004) Morphology and connections of nucleus isthmi pars magnocellularis in chicks (Gallus gallus). J Comp Neurol 469:275-297.

Wang Y, Luksch H, Brecha NC, Karten HJ (2006) Columnar projections from the cholinergic nucleus isthmi to the optic tectum in chicks (Gallus gallus): a possible substrate for synchronizing tectal channels. J Comp Neurol 494:7-35.

Williams B, Vanegas H (1982) Tectal projections in teleosts: responses of some target nuclei to direct tectal stimulation. Brain Res 242:3-9.

Xue HG, Yamamoto N, Yoshimoto M, Yang CY, Ito H (2001) Fiber connections of the nucleus isthmi in the carp (Cyprinus carpio) and tilapia (Oreochromis niloticus). Brain Behav Evol 58:185-204. 